DOI: 10.1136/annrheumdis-2019-eular.5451

\section{FRI0342 EROSIVE OSTEOARTHITIS IN PATIENTS WITH SYSTEMIC SCLEROSIS}

Cristina Pijoan Moratalla, Jaime Arroyo Palomo, Carlos De la Puente Bujidos. Hospital Universitario Ramón YCajal, Rheumatology, Madrid, Spain

Background: Erosive ostearthritis (EO) is a rare but aggressive variant of hand osteoarthritis. Its prevalence in Europe is 3.3\% in men and $9.9 \%$ in women, affecting $15.5 \%$ of patients with hand osteoarthritis ${ }^{1,2}$. EO causes a significant loss of function in the hands, with more severe inflammatory signs and affecting almost exclusively the PIP and DIP joints, usually avoiding the TM and MCP. In systemic sclerosis (SSc), hands are commonly affected with pain and joint deformity that, added to sclerodactyly and the presence of digital ulcers, produce an important functional limitation. It has not been established yet whether the presence of the disease determines an increased risk for the development of erosive osteoarthritis.

Objectives: To determine the frequency of EO in patients with SSc seen in a tertiary hospital in Madrid and to compare it with the frequency observed in the large cohorts of healthy population (Framingham study ${ }^{1}$ ). Secondly analyze both the clinical and analytical factors that may be related to the presence of $\mathrm{EO}$ in these patients.

Methods: A descriptive, observational cross-sectional study was conducted. We included all patients with a diagnosis of systemic sclerosis attended in our Rheumatology Unit. A database was created including clinical and epidemiological data and all the available imaging tests to assess the presence of findings compatible with EO in interphalangeal hand joints were reviewed. Acroosteolysis lesions were not considered as EO. Finally, a descriptive analysis was carried out.

Results: The prevalence of EO in our cohort of SSc patients, although low, is higher than the estimated in general healthy population according to the large European studies, with $8.16 \%(12 / 147)$ of the patients affected. All the patients with EO were female, wih a higher age of presentation of SSc compared to patients without EO (66.72 vs 50.72 years). EO was more prevalent in patients with limited skin involvement (75\% vs $62 \%$ ) and they had a higher frequency of telangiectasias in the typical locations. Likewise, patients with $\mathrm{EO}$ had more frequently positive AMA (25\% vs $8.88 \%$ ) and calcinosis (33\% vs $17.77 \%)$. The frequency of ANA, Raynaud's phenomenon and interstitial lung disease was similar in both groups. No patients with positive Ro or La presented EO.

Conclusion: Although it is an uncommon variant of hand osteoarthritis, in our cohort a higher prevalence of EO was observed in patients with SSc compared to the healthy general population. In our group, the most associated risk factors were female sex, advanced age at the diagnosis of SSc, the presence of AMA and calcinosis, regardless of its location. The frequency of pulmonary involvement and Raynaud's phenomenon was similar in both groups.

\section{REFERENCES:}

[1] I.K. Haugen, M. Englund, P. Aliabadi, et al. Prevalence, incidence and progression of hand osteoarthritis in the general population: The Framingham Osteoarthritis Study. Ann Rheum Dis, 70 (2011), pp. 1581-1586.

[2] W.Y. Kwok, M. Kloppenburg, F.R. Rosendaal, et al. Erosive hand osteoarthritis: Its prevalence and clinical impact in the general population and symptomatic hand osteoarthritis. Ann Rheum Dis, 70 (2011), pp. 12381242.

Disclosure of Interests: None declared

DOI: 10.1136/annrheumdis-2019-eular.3398

\section{FRI0343 EVALUATION OF CAROTID HEMODYNAMIC PARAMETERS AND PLAQUES BY DOPPLER ULTRASOUND IN PATIENTS WITH SYSTEMIC SCLEROSIS}

Isidro Sanz Pérez ${ }^{1}$, Fernando Martínez-Valle ${ }^{1}$, Alfredo Guillén del Castillo ${ }^{1}$, Olimpia Orozco-Galvez ${ }^{1}$, Eduardo L. Callejas-Moraga ${ }^{2}$, Vicent Fonollosa-Pla ${ }^{1}$, Carmen Pilar Simeón-Aznar ${ }^{1} .{ }^{1}$ Vall d'Hebron, Internal Medicine. Unit of autoinmune diseases, Barcelona, Spain; ${ }^{2}$ Hospital Parc Taulí, Internal Medicine. Unit of autoinmune diseases, Sabadell, Spain

Background: Carotid Doppler-ultrasound is useful for the detection of subclinical atheromatosis(1), and also for the evaluation of hemodynamic characteristics of carotid arteries(2).
Objectives: The aim of this study is to evaluate the hemodynamic parameters of carotid arteries and its relation with vascular related Systemic Sclerosis (SSc) complications and subclinical atheromatosis.

Methods: 157 patients with SSc of the cohort of Vall d'Hebron Hospital were included according to the ACR/EULAR 2013 criteria and LeRoy classification.

The left and right common carotid arteries (CCA), bulb and internal carotid arteries (ICA) were scanned using Doppler ultrasound for the detection of plaques and for the measurement of the Peak Systolic Velocity (PSV), End Diastolic Velocity (EDV), Pulsatility Index (PI), Resistance Index (RI) and Systole/Diastole ratio (S/D), using the software incorporated in GE Healthcare's Vivid I equipment.

Results: 157 patients were included, 132 women $(84.1 \%)$, the mean age was 56 years old (range 20-83) and the mean of years of disease evolution was 19 years (range 3-57). 64.2\% were SSc limited subset, 20.9\% SSc diffuse subset, $9.5 \%$ SSc sine scleroderma and $4.7 \%$ early SSc subset. $49.3 \%$ had digital ulcers, $41.9 \%$ had interstitial lung disease and $14.2 \%$ had pulmonary hypertension.

There were no statistically significant differences in hemodynamic parameters in relation to Raynaud's phenomenon, digital ulcers or pulmonary hypertension

Seventy-five patients $(47.7 \%)$ had carotid plaques. Patients with plaques had lower CCA PSV $(66.8 \mathrm{~cm} / \mathrm{s}$ vs $76.7 \mathrm{~cm} / \mathrm{s}, \mathrm{p}<0.01, \mathrm{Cl} 4.62-14.5)$, lower CCA EDV $(15.3 \mathrm{~cm} / \mathrm{s}$ vs $19.99 \mathrm{~cm} / \mathrm{s} \mathrm{p}<0.01, \mathrm{Cl} 2.88-6.49)$, higher CCA PI (1.69 vs. $1.55, \mathrm{p}<0.05 ; \mathrm{Cl} 0.02-0.26)$ and higher CCA RI $(0.77$ vs $0.73 \mathrm{p}<0.01 \mathrm{Cl} 0.02-0.05)$. These patients also had lower ICA EDV $(22.9 \mathrm{~cm} / \mathrm{s}$ vs $26.5 \mathrm{~cm} / \mathrm{s}, \mathrm{p}<0.01 ; \mathrm{Cl} 1.01-6.11)$, higher ICA PI (1.43 vs 1.32, $\mathrm{p}<0.05 \mathrm{Cl} 0.01-0.22)$ and higher RI0.71 vs $0.68 \mathrm{p}<0,05 \mathrm{Cl} 0.01$ $0.05)$, without statistically significant differences in ICA PSV $(79.75 \mathrm{~cm} / \mathrm{s}$ vs $84.24 \mathrm{~cm} / \mathrm{s}$ p: 0.21 ) nor in the ratio PSV/EDV.

Ratio ICA PSV/CCA PSV was calculated, without showing significant differences in the presence of plaques or vascular manifestations of the SSc.

The PSV greater than $120 \mathrm{~m} / \mathrm{s}$, as an isolated measure, did not show statistically significant differences related to the presence of plaques. The PSV greater than 150 showed statistically significant differences $(p<0.01$ $\mathrm{Cl}$ 0.05-0.23), showing a large specificity 0.98 but a very low sensitivity 0.15 for the detection of plaques.

Conclusion: In our study we have not found relation between carotid hemodynamic parameters and microvascular related SSc complications such as Raynaud's phenomenon, the presence of digital ulcers or pulmonary hypertension.

Patients with SSc and atheromatous disease have a characteristic carotid hemodynamic profile consisting in lower PSV and EDV, and higher P and RI, both at CCA and at ICA. The presence of increased PI and RI in patients with plaques, could suggest a primary damage of the vascular wall in patients with SSc. More studies are needed to determine if these data are the cause or a consequence of the presence of plaques. In our study the PSV greater than $150 \mathrm{~cm} / \mathrm{s}$ isolated shows a high specificity for the presence of plaques.

\section{REFERENCES}

[1] Sanz Pérez I. et al. Subclinical cardiovascular disease and Systemic Sclerosis: A comparison between risk charts, quantification of coronary calcium and carotid ultrasonography. Autoimmun Rev. 2018;17(9):900-5.

[2] Staub D. et al. Prediction of cardiovascular morbidity and mortality: Com parison of the internal carotid artery resistive index with the common carotid artery intima-media thickness. Stroke. 2006;37(3):800-5.

Disclosure of Interests: None declared DOI: 10.1136/annrheumdis-2019-eular.4789

\section{FRI0344 SEXUAL FUNCTION IN GERMAN WOMEN WITH SYSTEMIC SCLEROSIS COMPARED TO WOMEN WITH SYSTEMIC LUPUS ERYTHEMATODES AND EVALUATION OF A SCREENING TEST}

Marc Schmalzing ${ }^{1}$, Lena Friederike $\mathrm{Nau}^{2}$, Michael Gernert ${ }^{1}$, Eva Christina Schwaneck ${ }^{1}$, Sebastian Saur ${ }^{2}$, Hans-Peter Tony ${ }^{1}$, Melanie Henes ${ }^{3}$, Jörg Henes ${ }^{2}$. 'University Hospital Würzburg, Rheumatology/Clinical Immunology, Würzburg, Germany, ${ }^{2}$ University Hospital Tübingen, Rheumatology, Tübingen, Germany, ${ }^{3}$ University Hospital Tübingen, Gynaecology, Tübingen, Germany

Background: Few studies have been conducted to address the impact of systemic lupus erythematodes (SLE) or systemic sclerosis (SSc) on sexual function $(1,2)$, and so far none in Germany. 